\title{
EL YACIMIENTO PROTO HISTÓRICO DE EL CASTELLAR(CAÑETE DE LAS TORRES. CÓRDOBA)
}

\author{
José Antonio MORENA LÓPEZ (*)
}

Tras varios años dedicados al estudio del poblamiento antiguo en el término municipal de Cañete de las Torres, provinciade Córdoba, creemos estar, hoy día, en disposición de reconocer, las líneas generales del devenir histórico de las poblaciones autóctonas de esta zona de la campiña cordobesa, desde sus inicios hasta la época medieval-moderna (SERRANO-MORENA, 1984; MORENA, 1987). En 1987 contamos con una subvención y con el consiguiente permiso, por parte de la Dirección General de Bienes Culturales de la Junta de Andalucía, para llevar acabo una Prospección Arqueológica Superficial en el término de Cañete. Fruto de dicho trabajo fue la localización de un total de 118 yacimientos y la recogida de abundante material arqueológico \{MORENA, 1990 a) actualmente depositado en el Museo Histórico de la localidad.

De entre todos los períodos constatados, que van desde el Calcolítico hasta la época musulmana, uno de los más atractivos es el correspondiente al Bronce Final, y más concretamente al llamado Bronce Final Reciente y Fase Orientalizante, un período que comprende desde el s. VIII a.C. hasta comienzos del s. V a.C. y que también se puede denominar Horizonte tartésico o protohistórico. Quizás el fenómeno más llamativo que en dicho momento se produce, consiste en un extraordinario aumento de los efectivos demográficos -crecimiento ya constatado en gran parte de Andalucía y sobre todo en el Bajo Guadalquivir (AUBET, 1986; ESCACENA, 1983). Este "boom" poblacional se traduce en un elevado número de poblados, consecuencia probable tanto de un crecimiento natural de las comunidades preexistentes (ESCACENA, 1983) como de aporte exógeno de población (GONZÁLEZ WAGNER, 1983) pues no debe olvidarse que es precisamente ahora cuando la colonización fenicia alcanza su verdadera dimensión (ARTEAGA, 1987 a).

En Cañete hemos documentado hasta 35 lugares de interés arqueológico pertenecientes aesta época, la mayoría de ellos concentrados en la zona meridional del término, en el área de influencia del gran oppidum de Torreparedones (Castro del Rfo-Baena). De ellos

(*) Museo Local de Cañete de las Torres, Córdoba. 
hemos elegido El Castellar con el objeto de analizarlo monográficamente y presentarlo como un modelo, un ejemplo de habitat prolohistórico, y dejar para un próximo trabajo el estudio global de todos los asentamientos del Bronce Final-Período Orientalizante conocidos en el término de Cañete. Se puede afirmar que casi el $90 \%$ de los yacimientos encuadrables en este período que hemos localizado en la Campiña oriental de Córdoba presentan unas características muy similares en loqueaextensión, materiales y patrón de asentamiento se refiere (MORENA, 1990 b; MORENA-SÁNCHEZ DE LA ORDENGARCIA, 1990; MURILLO-MORENA, ep). Su superficie oscila entre 100 y $200 \mathrm{ml}$ están ubicados en zonas de ladera, casi siempre junto a algún manantial o curso fluvial próximo, y los materiales se repiten incansablemente en todos y cada uno de ellos cerámicas a mano toscas, decoradas o lisas, $y$ a torno pintadas y de pasta gris-. Se trata de pequeños núcleos rurales, la mayoría fundados ex novo hacia los s. VIII-VII a.C. Su concentración en torno al gran oppidum de Torreparedones plantea la hipótesis de que las causas de este poblamiento de carácter rural, hasta ahora poco o nada valorado por desconocido, estriben en un crecimiento natural de la población preexistente, sin descartar aunque no se tengan todavía pruebas arqueológicas firmes, la posibilidad de un aporte poblacional exógeno en esta zona en relación con la colonización fenicia (GONZÁLEZ WAGNER-ALVAR, 1989). Por estas fechas, y sobre todo durante las centurias siguientes, Torreparedones debió ocupar además un lugar destacado, desde el punto de vista político y del control del territorio dentro de lared primaria del poblamiento en el sureste de Córdoba (MURILLO-QUESADA-VAQUERIZO-CARRILLO-MOREN A, 1989).

El Castellar, topónimo que indica per se la existencia de restos arqueológicos, está situado en la Hoja 17-38 (945) del M.M.E. Esc. 1/50.000, a unos $11 \mathrm{~km}$. al S-SO de Cañete y a unos 500 ra. al O de la CV. 149 de Castro del Río a Cañete de las Torres (Figs. 1 -2). Sus coordenadas U.T.M. son: $x=377.975 ; y=4.183 .100 ; z=420$. Como características típicas que pueden hacerse extensibles al resto de asentamientos podemos señalar: su reducida extensión entre 100 y $200 \mathrm{~m}^{2}$, situación en ladera, presencia de agua en sus cercanías -al O tenemos el arroyo de la Fuente de los Pastores, al E el de las Monjas y al SE la Fuente de la Sierra- y por último, el material arqueológico. La topografía del terreno delata la presencia bajo él de restos de muros, muy superficiales por cieno, y que se dejan notar con claridad durante el laboreo del terreno, aunque no es posible reconocer qué tipo de estructura conforman, ni tampoco qué técnica se empleó en su construcción.

Todo el materia] recogido procede de superficie y es de tipo cerámico, muy fragmentado además, como consecuencia de las continuas y profundas labores agrícolas. A modo de ilustración hemos realizado una selección de las piezas más significativas, ya que el materia] de que disponemos es muy abundante debido a las numerosas visitas realizadas al yacimiento siempre en condiciones óptimas para la prospección. Se pueden diferenciar dos grandes grupos: uno en el que englobamos las cerámicas modeladas a mano (Figs. 35) y otro en el que se incluyen las producciones a tomo (Figs. 6-11). 
Dentro del primero existen cerámicas lisas y decoradas, ambas fabricadas con un barro poco depurado y con abundantes desgrasantes, resultando excesivamente frágiles al haber sido cocidas a bajas temperaturas. Sus superficies suelen ser muy toscas, de aspecto rugoso realizado intencionalmente. Es posible que muchos fragmentos toscos correspondan a grandes vasos cuya parte superior se encuentra alisada, espatulada o incluso bruñida, al ser la más visible, mientras que la parte inferior rugosa quedaría bajo tierra. Sin embargo, la superficie interna es normal que esté alisada; a veces presentan en la zona del hombro una decoración estilizada a base de insiciones realizadas con un instrumento punzante (Fig. 4, n ${ }^{\circ} 3$; Fig. 5, n ${ }^{\circ}$ ) ocon la misma uña (Fig. 3, no 4; Fig. 5, no 7 ), objetos de sección circular (Fig. 5, $\mathrm{n}^{\mathrm{f}^{\mathrm{0}}}$ 2) o líneas de impresiones digitales (Fig. 4, $\mathrm{n}^{\mathrm{a}} 2$ ). La DPA se reduce a pequeños mamelones y a las denominadas "asas de herradura" (Fig, 4, $\mathrm{n}^{\mathrm{o}} 1$ ). Conviene señalar además que, en ocasiones, un mismo vaso puede estar decorado con distintas técnicas y motivos (Fig. $3, \mathrm{n}^{\circ} 4$; Fig. $4, \mathrm{n}^{9} 1$ etc.). Desde el punto de vista tipológico se da cierta variedad formal aunque la más común es la olla, de cuerpo globular, base rectay borde corto y vuelto al exterior. Entre otras piezas fabricadas con esta misma cerámica indicamos un soporte (Fig. 5, n ${ }^{\circ}$ ) y varias fusayolas (Fig. 3, n ${ }^{\circ} 5-7$ ). El soporte es similar, tanto porsus dimensiones como por su sección aotro procedente del yacimiento de Visillos (I), también de Cañete (MORENA, 1990 a). Las fusayolas son de sección y tamaño diferentes: hemiesférica y de base cóncava (Fig. 3, nº 5), bitroncocónica (Fig. 3, $\left.\mathrm{n}^{\mathrm{o}} 7\right)$.

Sobre el origen de este tipo de cerámica tosca se ha escrito y discutido mucho, siendo hoy generalmente aceptada la tesis de que se trata de un producto autóctono, básicamente tartésico (PELLICER. 1977 y 1982; RUIZ-FERNANDEZ, 1986).

Respecto el segundo grupo de cerámicas también se pueden establecer dos tipos: las pintadas y las grises, significando ambas el reflejo de una de las aportaciones más novedosas de los colonos semitas: el torno del alfarero, pues a partir de ahora la producción cerámica se va a incrementar de modo notable, las piezas serán más resistentes y su estéricamás refinada. Entre las pintadas encontramos distintos tipos de vasos, platos y ánforas. Por lo general, estas cerámicas tienen un espectro cronológico muy amplio, aunque a veces es posible afinar su fecha en base a la utilización o no de la bicromía y el engobe. Algunos recipientes (Fig. 6, $n^{\circ} 7$; Fig. 7, $n^{\circ} 6$; Fig. 9, $n^{\circ} 3$ ) se caracterizan por tener un cuerpo ovoide, de boca ancha y reborde exterior del que suelen partir asas (BELENPEREIRA, 1985) y tienen una cronología que abarca desde el s. VIII a.C. hasta el s. III a.C en la Baja Andalucía, debiendo corresponder los nuestros a los ejemplares más antiguos pues presentan engobe y decoración bícroma a base de líneas rectas horizontales. Otras por el contrario (Fig. 9, n ${ }^{\circ}$ 2; Fig. 10, n 10) pueden ser mucho más tardías (PEREIRA, 1988). Las ánforas (Fig. 8, no 2-4), cuya función era la conservación y el transporte de alimentosperecederos, seencuentran en todos los poblados protohistóricos del Mediodía peninsular como consecuencia de los intercambios comerciales entre fenicios e indígenas. 
En el Ceno Macareno se han hallado en tal cantidad que ha sido factible establecer una clara evolución tipológica (PELLICER, 1978). Los cuencos, que apenas evolucionan tipológicamente, se pueden fechar desde el s. VII a.C. hasta la época romana (Fig. 10, $\mathrm{n}^{\circ}$ 2-3). Las asas más abundantes son las tubulares simples \{Fig. 6, nº 1; Fig. 7, no 1) que corresponden generalmente a ánforas feno-púnicas, pero también las hay geminadas (Fig. 7, n 2 ; Fig. 9, n ${ }^{\circ}$ 5) y trígeminadas (Fig. 6, n⿳0 5), éstas dos últimas asociadas a contextos antiguos de los s. VII-VI a.C. Un tipo de asa no muy común es el "asa de cesta" (Fig. 8, $\mathrm{n}^{\mathrm{a}}$ 6-7), de sección circulary transversal a la boca del vaso. Los ejemplares conocidos de la cuenca media del Guadalquivir (Llanete de los Moros y Colina de los Quemados) se pueden fechar en el s. VI a.C. (LUZON-RUIZ, 1973; MARTIN DE LA CRUZ, 1988). En la Atalayuela, lugar del término de Alcaracejos, al $\mathrm{N}$ de la provincia, se han recogido varios ejemplares de estas asas, también llamadas diametrales, que se han datado en el s. IV a.C. (LOPEZ PALOMO, 1987), aunque el contexto del yacimiento parece más bien del s. VIa.C.

Los motivos decorativos que adornan estas cerámicas son de carácter geométrico, a base de círculos concéntricos (Fig. 6, n $\mathrm{n}^{\circ}$; Fig. 9, nº 6), líneas sinuosas verticales o aguas (Fig. 6, nº 2, Fig. 10, no 4), así como bandas paralelas alternas (Fig. 7, n 1 ; Fig. 9, no 2 3). Entre la cerámica a tomo presentamos una pieza no pintada, del tipo de las conocidas fichas recortadas o discoidales muy frecuentes en los yacimientos ibéricos (CASTRO, 1978).

La cerámica gris, conocida indistintamente como gris de la Costa, gris de Occidente, etc. está presente en todos los focos tartésicos del sur peninsular desde el s. VIII a.C, y a pesar de toda una serie de estudios a ella dedicados aún plantea serias dudas sobre su filiación cultural. Las últimas investigaciones apuestan por un origen local y propio del mundo tartésico (ROOS, 1982; CARO, 1989). Se trata de una cerámica de pasta depurada, bien cocida, muy compacta y de superficie cuidada, a veces de aspecto casi metálico. Las primeras cerámicas grises del área tartésica se han relacionado, en ocasiones, con las producciones indígenas amano, viendoen ellas una versión a torno de formas tradicionales, es decir, un intento por parte de la población tartésica de adoptar el tomo del alfarero a sus propias producciones (DOMÍNGUEZ DE LA CONCHA et alii, 1989). En El Castellar seobserva este fenómeno: hay algunas formas de cerámica gris que también se dan en cerámica a mano (Fig. 5, n ${ }^{\circ}$ 9). Esta especie cerámica adquiere en este yacimiento un auge inusitado, con cierta variedad formal: platos de bordes cóncavos y carenados y cuencos de borde simple engrosado al interior; las bases son planas, ligeramente levantadas (Fig. 11). Destaca un fragmento, pereteneciente a un vaso de tendencia semiesférica con paredes verticales, cuya característica principal son las estrías u ondulaciones que presenta al exterior bajo el borde (Fig. 11, $\mathrm{n}^{\circ}$ 10). Aunque esta forma se ha documentado en distintas variedades cerámicas: bamizrojo, pintadas polícromas, hasta la fecha sólo se conoce un fragmento de cerámica gris hallado en el poblado del Cerro del Carambolo, 
datado en la primera mitad del s. VII a.C, (CARO, 1989), así mismo ofrecemos varios fragmentos pertenecientes a soportes de diferente tipología (Fig, 11, nº 1,14).

En cuanto a las actividades económicas desarrolladas por los habitantes de este asentamiento hay que citar junto a una incipiente industria textil documentada por las fusayolas, una intensa actividad centrada en la agricultura de tipo cerealistico, favorecida por la fertilidad del suelo, y que ha dejado su rastro en los numerosos molinos de mano barquiformes.

Como punto y final diremos, con gran cautela pues sólo contamos con material de superficie, que el período de vida de este lugar puede fijarse entre el s. VHI a.C. o comienzos del s. VII a.C. y el s. III a.C. aproximadamente. Los materiales que se encuentran en las estratigrafías de los yacimientos más próximos como la Colina de los Quemados (LUZON-RU1Z, 1973), Llanete de los Moros (MARTIN DE LA CRUZ, 1988), Los Alcores de Porcuna (ARTEAGA. 1987 b) y Torreparedones (CUNLIFFEFERNANDEZ, 1990) apoyan esta cronología. El abandono del poblado se produce con anterioridad a la llegada de los romanos.

\section{Bibliografía}

AUBET, M'.E. (1986): "Horizonte cultural protohistórico", Revista de Arqueología, Extra ${ }^{\circ} 1$. Tartessos, págs. 58 ss.

ARTEAGA, O. (1987 a): 'Perspectivas espacio-temporales de la colonización fenicia occidental. Ensayo de aproximación". Iberos, Jaén, págs. 206 ss.

ÍDEM (1987 b): "Excavaciones arqueológicas sistemáticas en el Cerro de los Alcores (Porcuna. Jaén). Informe preliminar sobre la camparla de 1985", Anuario Arqueológico de Andalucía, 11/1985, págs. 279 ss.

BELÉN, Ma; PEREIRA, J. (1985): "Cerámicas a tomo con decoración pintada en Andalucía", Huelva Arqueológica, Vil, págs. 307 ss.

CASTRO, Z. (1978): "Piezas discoidales en yacimientos ibéricos del NE de Cataluña", Cypsela, II, págs. 173 ss.

CARO, A. (1989): Cerámica gris a torno tartesia, Cádiz.

CUNLIFFE. B; FERNANDEZ, M'.C. (1990): "Torreparedones (Castro del RíoBaena. Córdoba). Informe preliminar. Campaña de 1987: Prospección Arqueológica con Sondeo Estratigráfico", Anuario Arqueológico de Andalucía, 11/1987, págs. 193 ss.

DOMÍNGUEZ DE LA CONCHA, et alii (1989): "Cerro de la Cabeza (Santiponce. Sevilla)", Noticiario Arqueológico Hispánico 30, págs. 119 ss.

ESCACEN A, J.L. (1983): "Problemas en tomo a los orígenes del urbanismo a orillas del Guadalquivir", Gades, 11, págs. 52 ss.

GONZÁLEZ WAGNER, C. (1983): "Aproximación al proceso histórico de Tartessos", Archivo Español de Arqueología, 56, págs. 3 ss. 
GONZÁLEZ WAGNER, C; ALVAR, J. (1989): "Fenicios en Occidente: la colonización agrícola",Rivista di studifenici,XVII, 1,págs. 61 ss.

LOPEZPALOMO.L.A. (1987): "Iberos y celtas en la penillanura de losPedroches", Revista de Arqueología, 69, págs. 37 ss.

LUZON, J.M»; RUIZ, D. (1973): Las raíces de Córdoba. Estratigrafía en la Colina de los Quemados, Córdoba.

MARTIN DE LA CRUZ, J.C. (1988): El Llanete de los Moros (Montoro. Córdoba). Excavaciones Arqueológicas en España, 151.

MORENA, J.A. (1987):" Aproximación a) estudio del poblamiento indígena y de la romanización en Cañete de las Torres (Córdoba)", Cañete de las Torres. Visión histórica de un pueblo andaluz. Córdoba.

ÍDEM (1990 a): "Informe preliminar de la Prospección Arqueológica de Superficie realizada en el término de Cañete de las Torres (Córdoba)", Anuario Arqueológico de Andalucía, 11/1987, págs. 108 ss.

ÍDEM (1990 b): "Asentamientos rurales de época tartésica en Baena (Córdoba)". VIH Congreso de la Asociación Hespérides de profesores-investigadores de Bachillerato de Andalucía, Baena, págs. 471 ss.

MORENA, J. A.; SÁNCHEZ DE LA ORDEN, M; GARCÍA, A. (1990): Prospecciones arqueológicas en la Campiña de Córdoba, Córdoba.

MURHXO, J.F.; MORENA,J.A. (ep): "El poblamientoruralen elArroyoGuadatín: un modelo de ocupación del territorio durante el Bronce Final y el Período Orientalizante en la cuenca media del Guadalquivir".

MURILLO, J.F.; QUESADA, F.; VAQUERIZO, D.; CARRILLO, J.R.; MORENA, J.A. (1989): "Aproximación al estudio del poblamiento protohistórico en el sureste de Córdoba: unidades políticas, control del territorio y fronteras", /// Coloquio Internacional de Arqueología Espacial, págs. 151 ss. Teruel.

PELLICER, M. (1980): "Ensayo de periodización tartesia y turdetana", Habis, 1011, págs. 307 ss.

(1978): "Tipología y cronología de las ánforas prerromanas del Guadalquivir según el Cerro Macareno (Sevilla)", Habis, 9, págs. 365 ss.

(1982): "Hacia una periodización del Bronce Final en Andalucía Occidental", Huelva Arqueológica, VI, págs. 41 ss.

PEREIRA, J. (1988): "La cerámica ibérica de la cuenca del Guadalquivir, I. Propuesta áe clasificación". Trabajos de Prehistoria, 45, págs. 143 ss.

ROOS, A.Ma . (1982): "Acerca de la antigua cerámica gris a torno en la Península Ibérica", Ampurias, 44, págs. 43 ss.

RUIZ, D; FERNANDEZ J. (1986):' 'El yacimiento metalúrgico de época tartésica de San Bartolomé de Almonte (Huelva)", Huelva Arqueológica, VIH.

SERRANO, L; MORENA, J.A. (1984): Arqueología inédita de Córdoba y Jaén, Córdoba.

104 


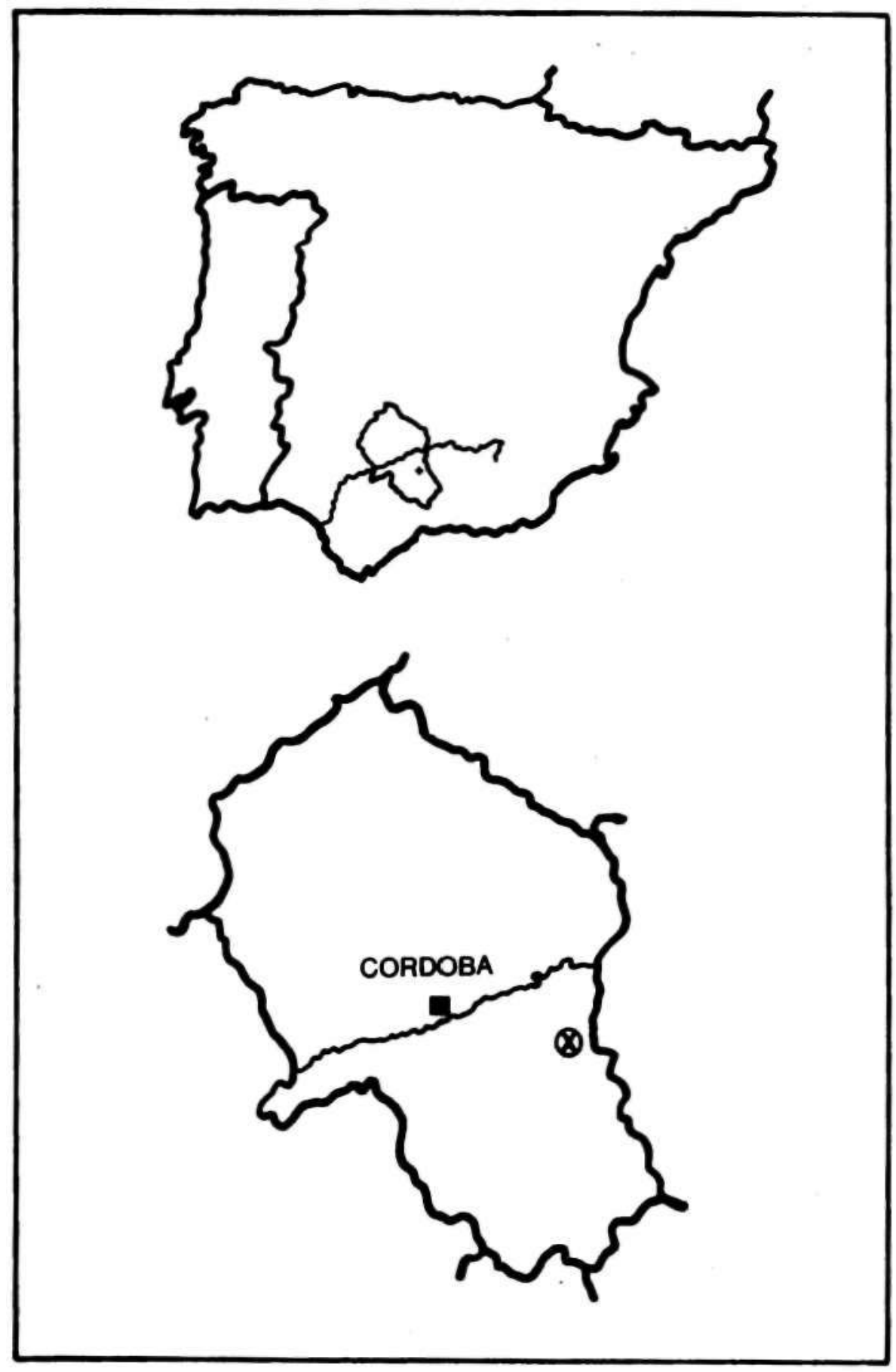

Figura 1 


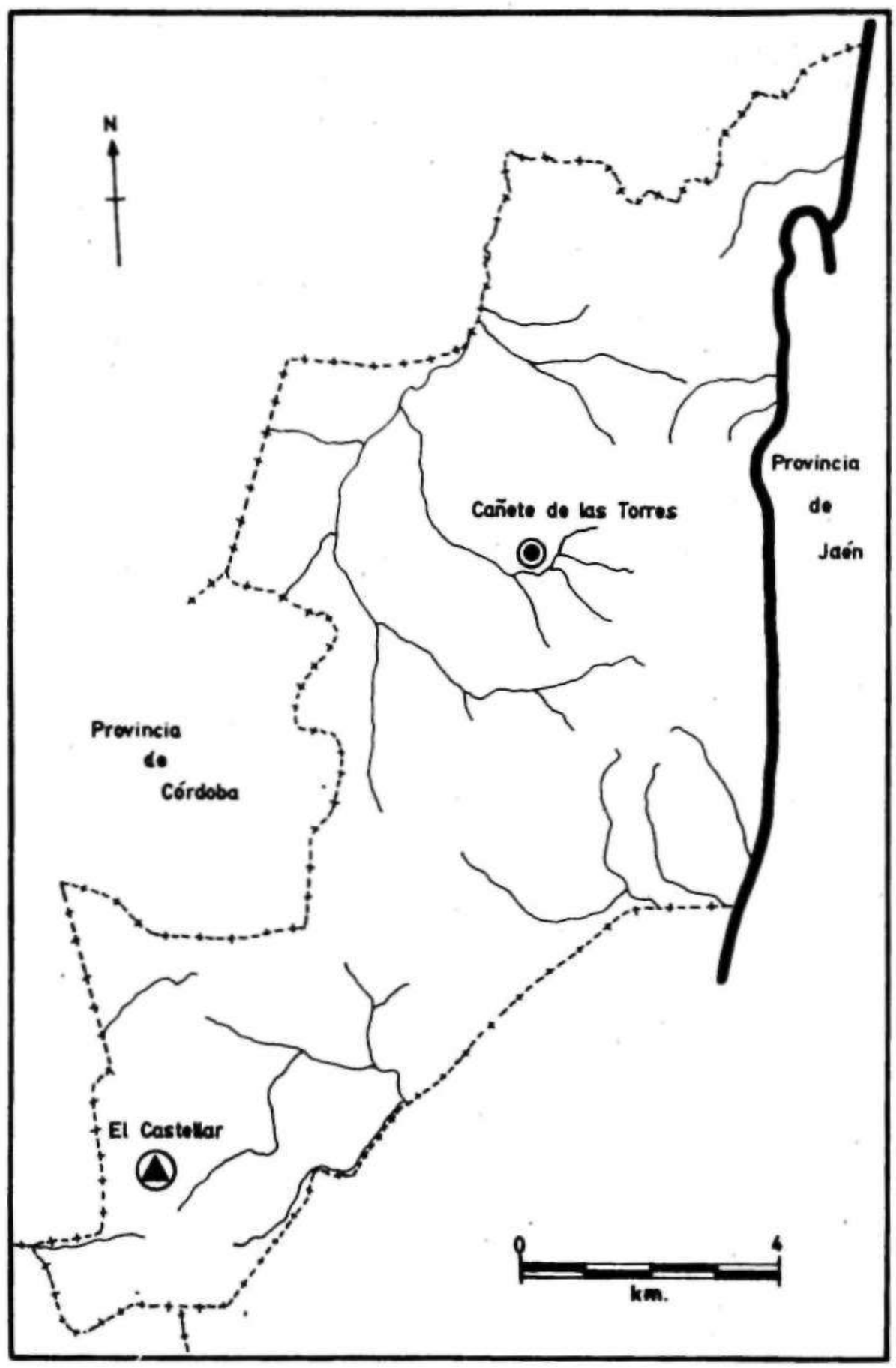

Figura 2 


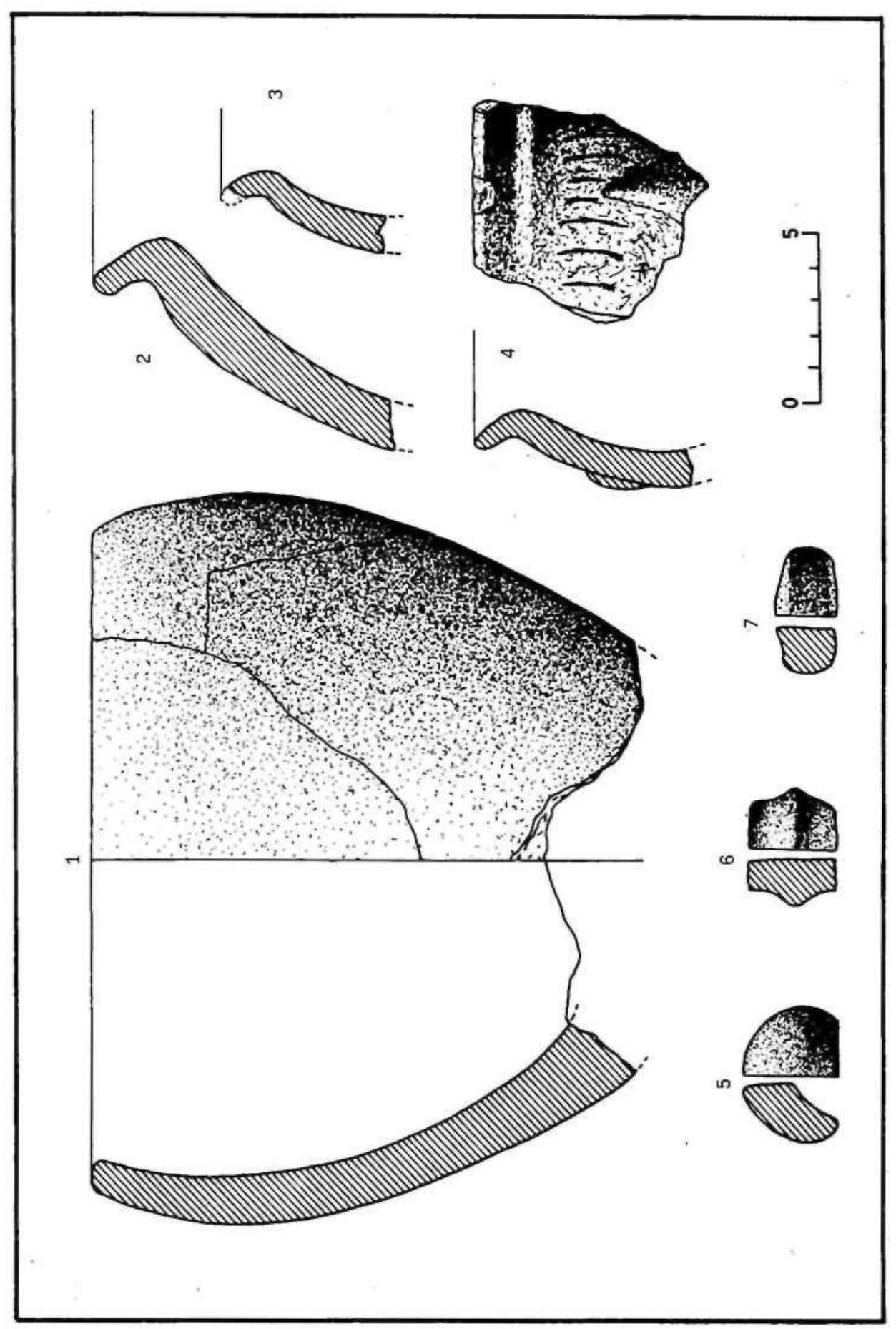

Figura 3

--- Grupo de investigación P.A.I. HUM 236 | http://www.arqueocordoba.com/publ/anales.htm -107 


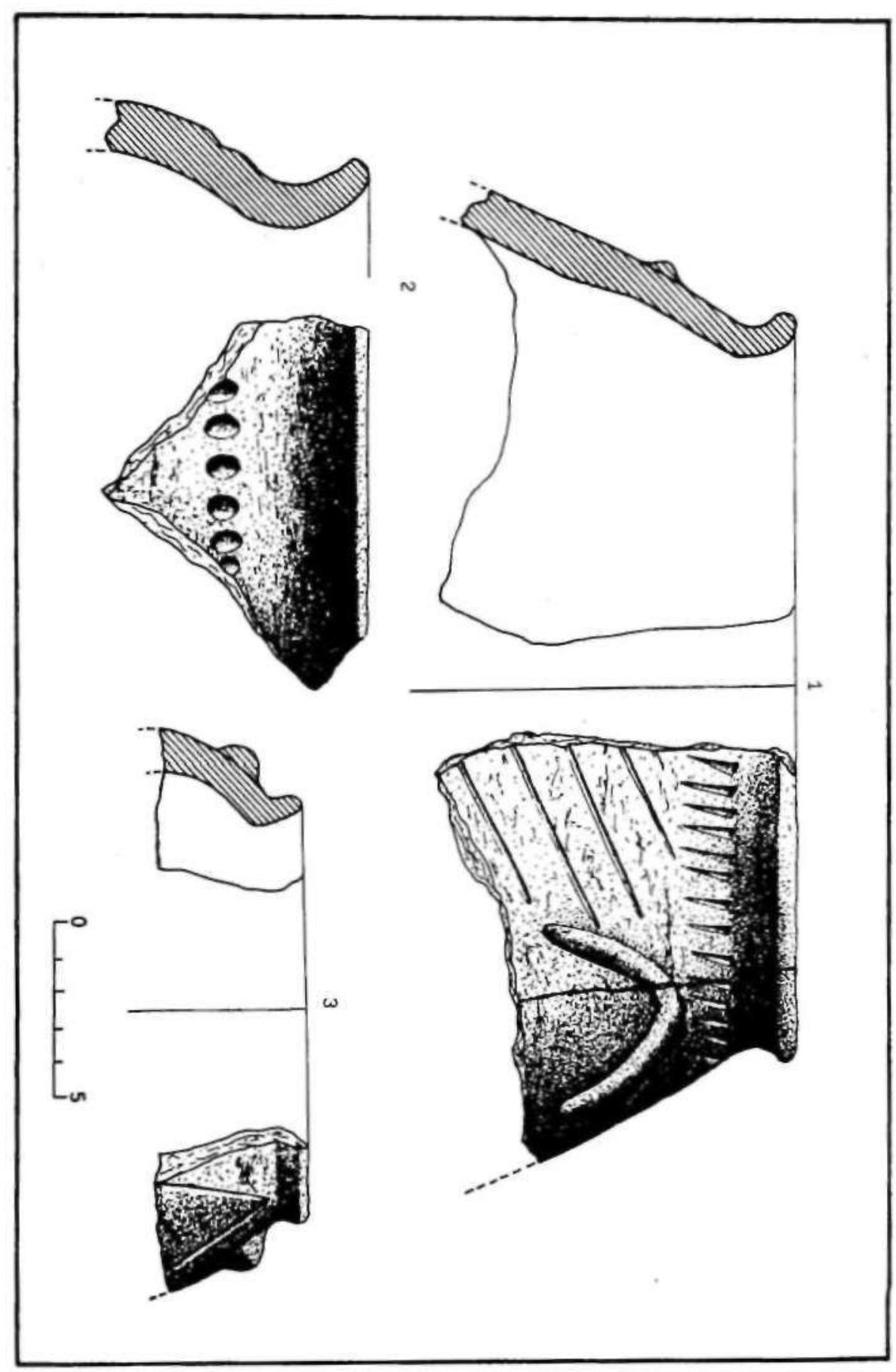

Figura 4

108

--- Grupo de investigación P.A.I. HUM 236 | http://www.arqueocordoba.com/publ/anales.htm --- 


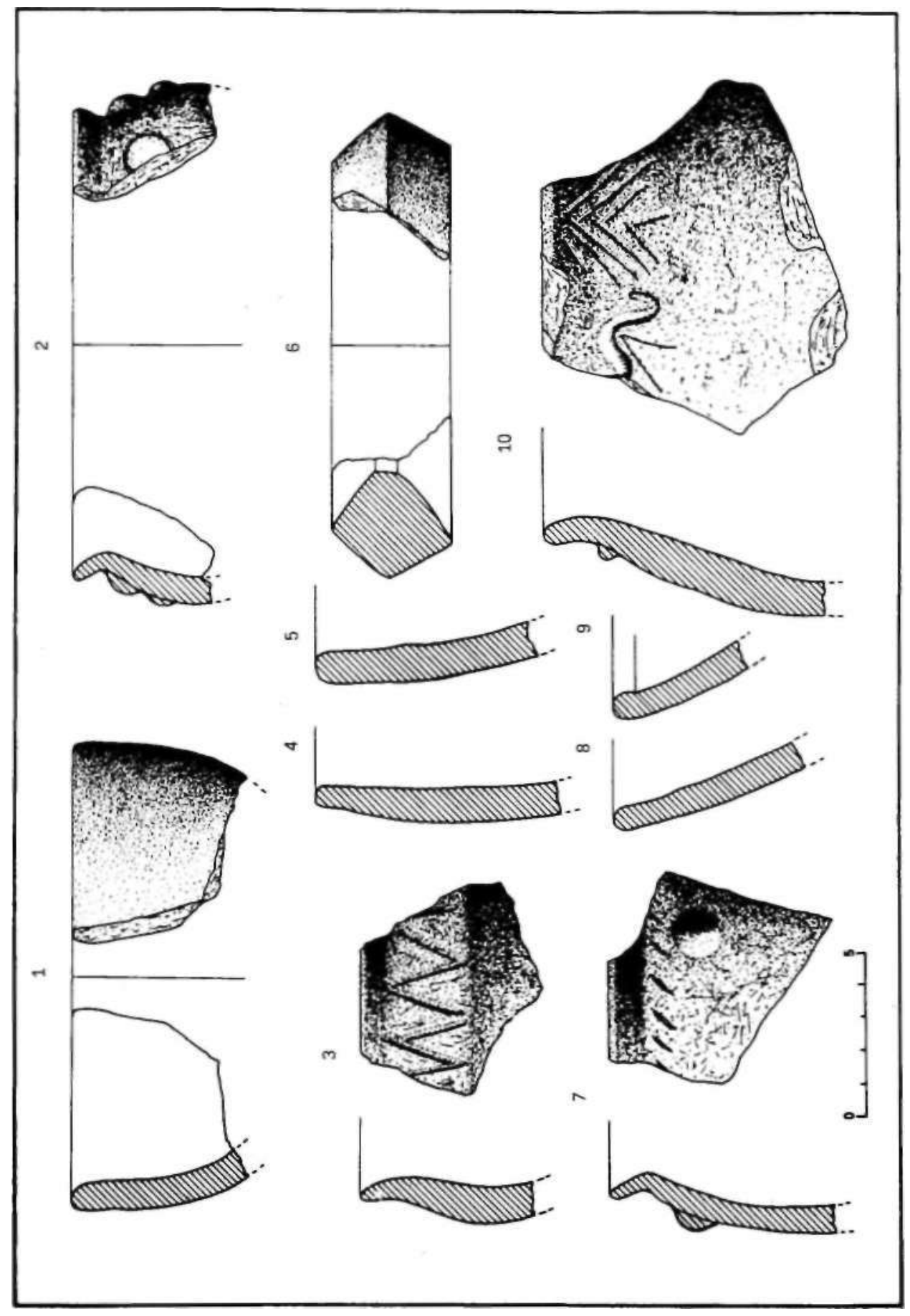

Figura 5 


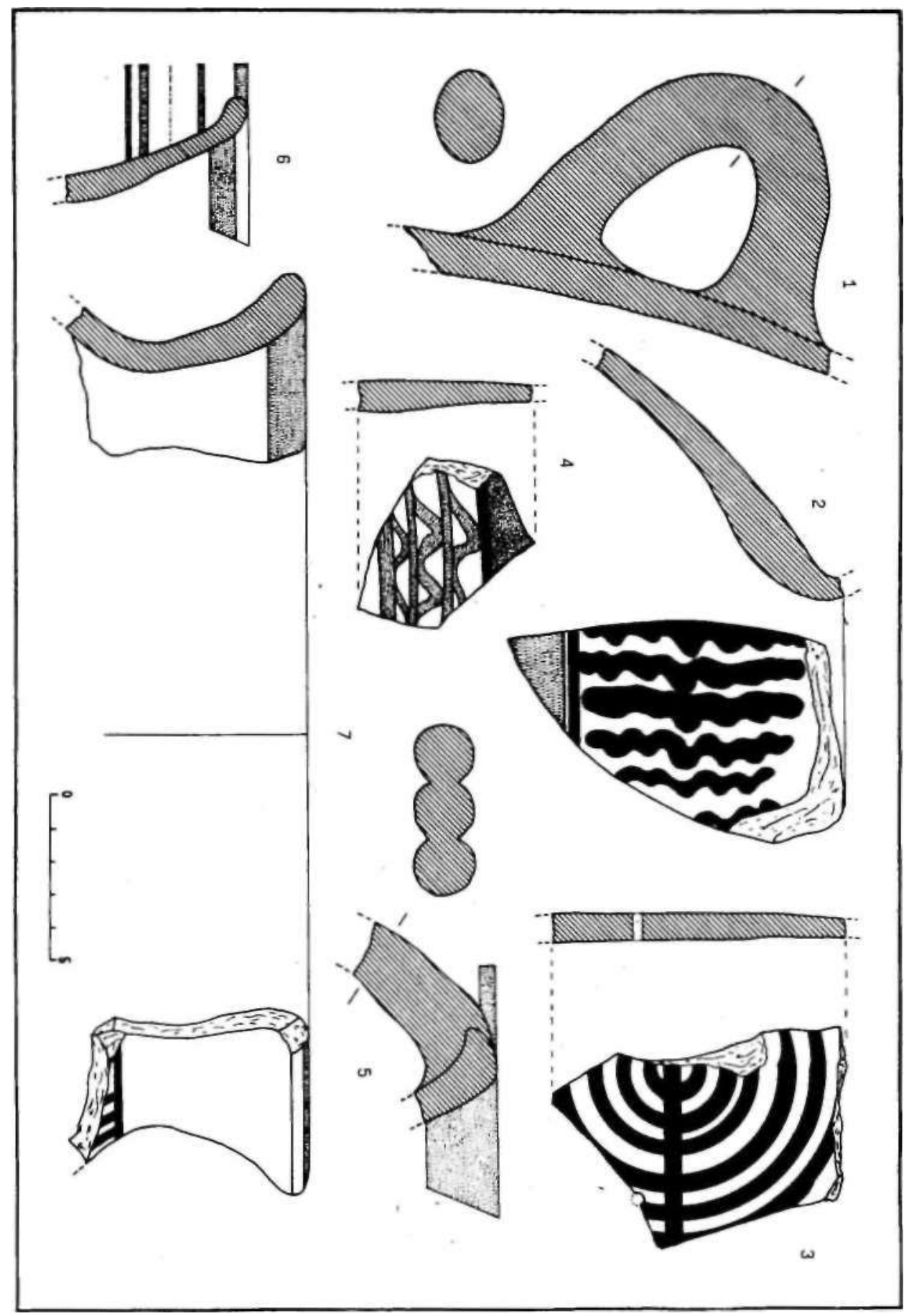

Figura 6 


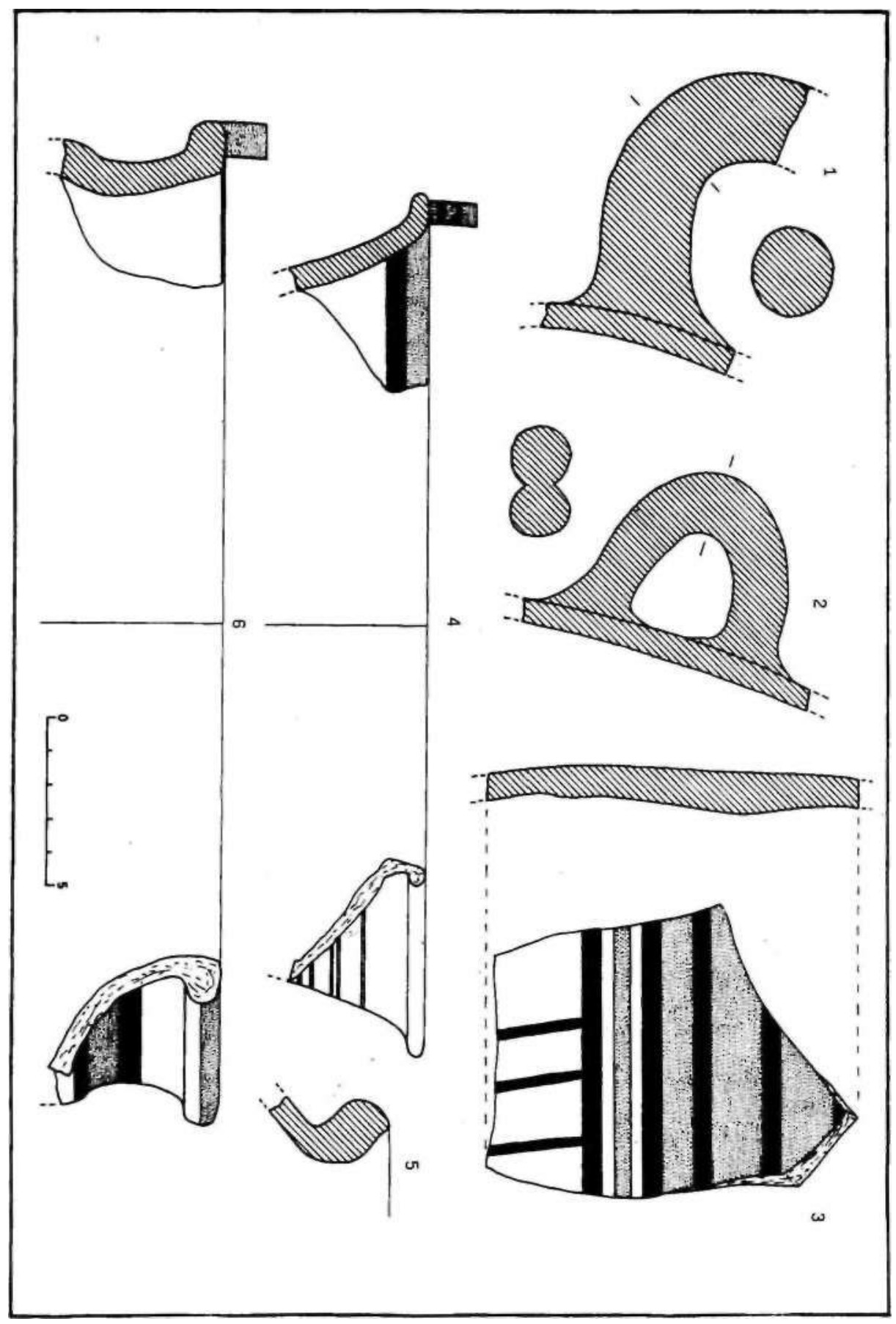

Figura 7 


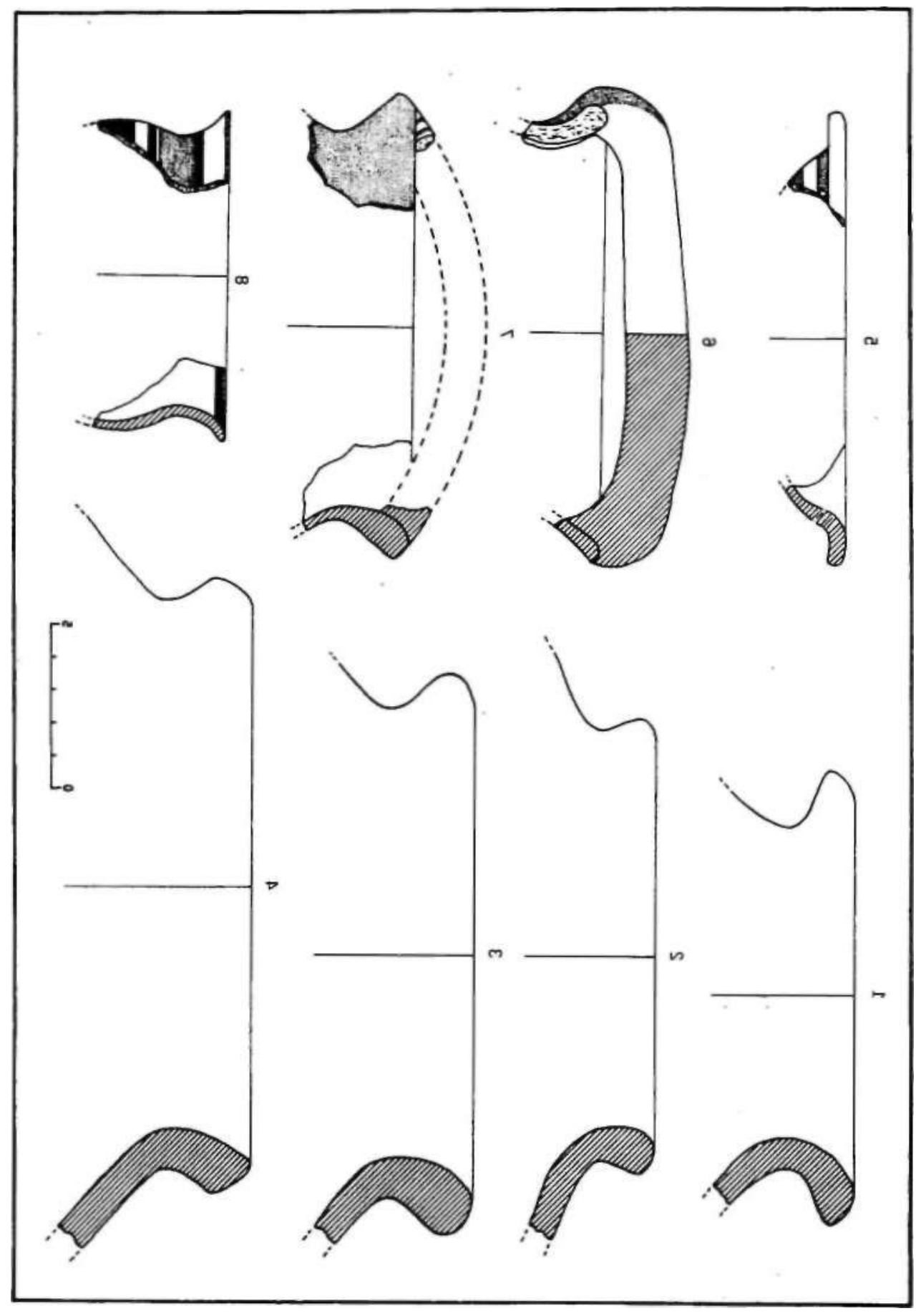

Figura 8 


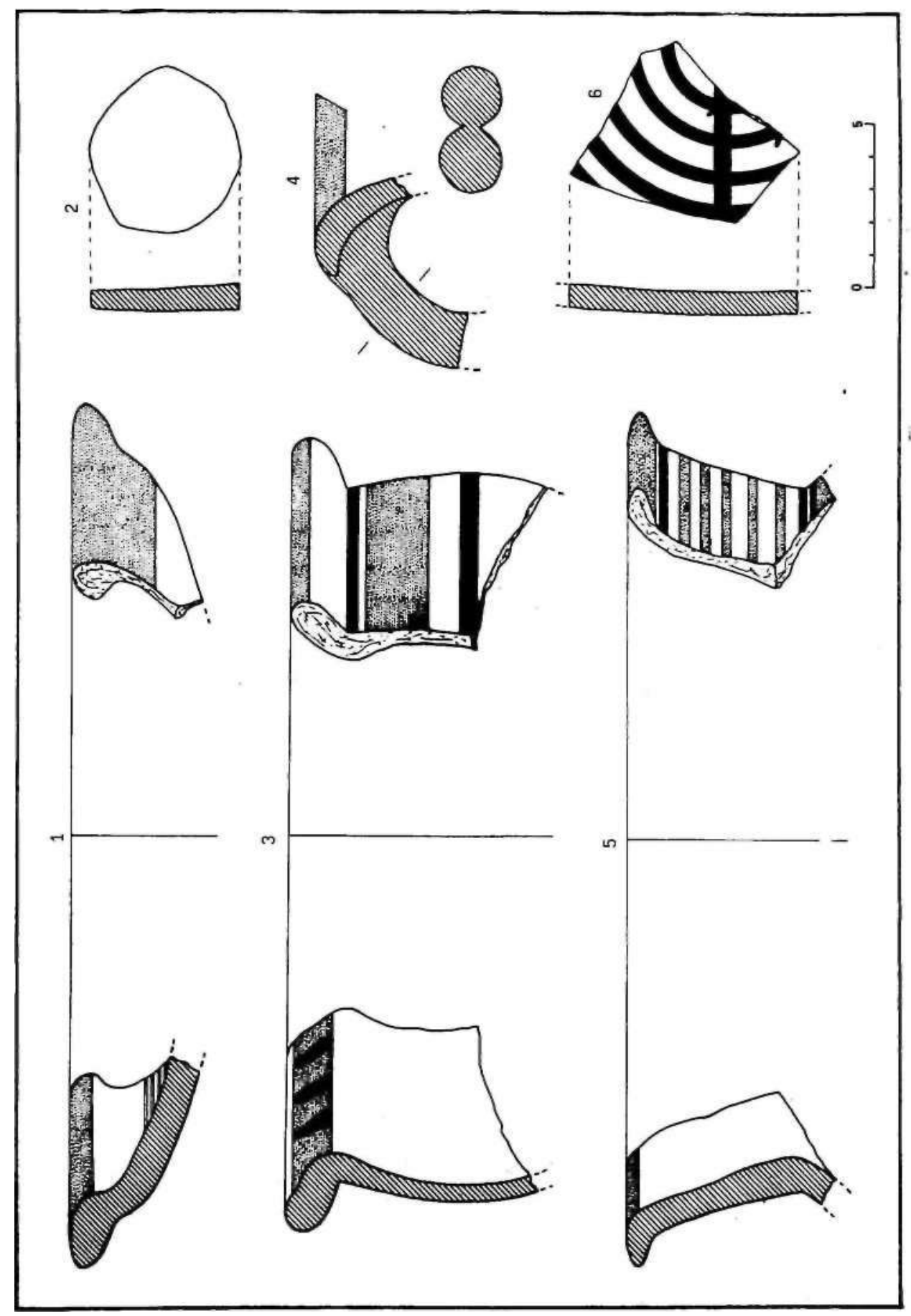

Figura 9

--- Grupo de investigación P.A.I. HUM 236 | http://www.arqueocordoba.com/publ/anales.htm ---113 
Figura 10

114

--- Grupo de investigación P.A.I. HUM 236 | http://www.arqueocordoba.com/publ/anales.htm --- 


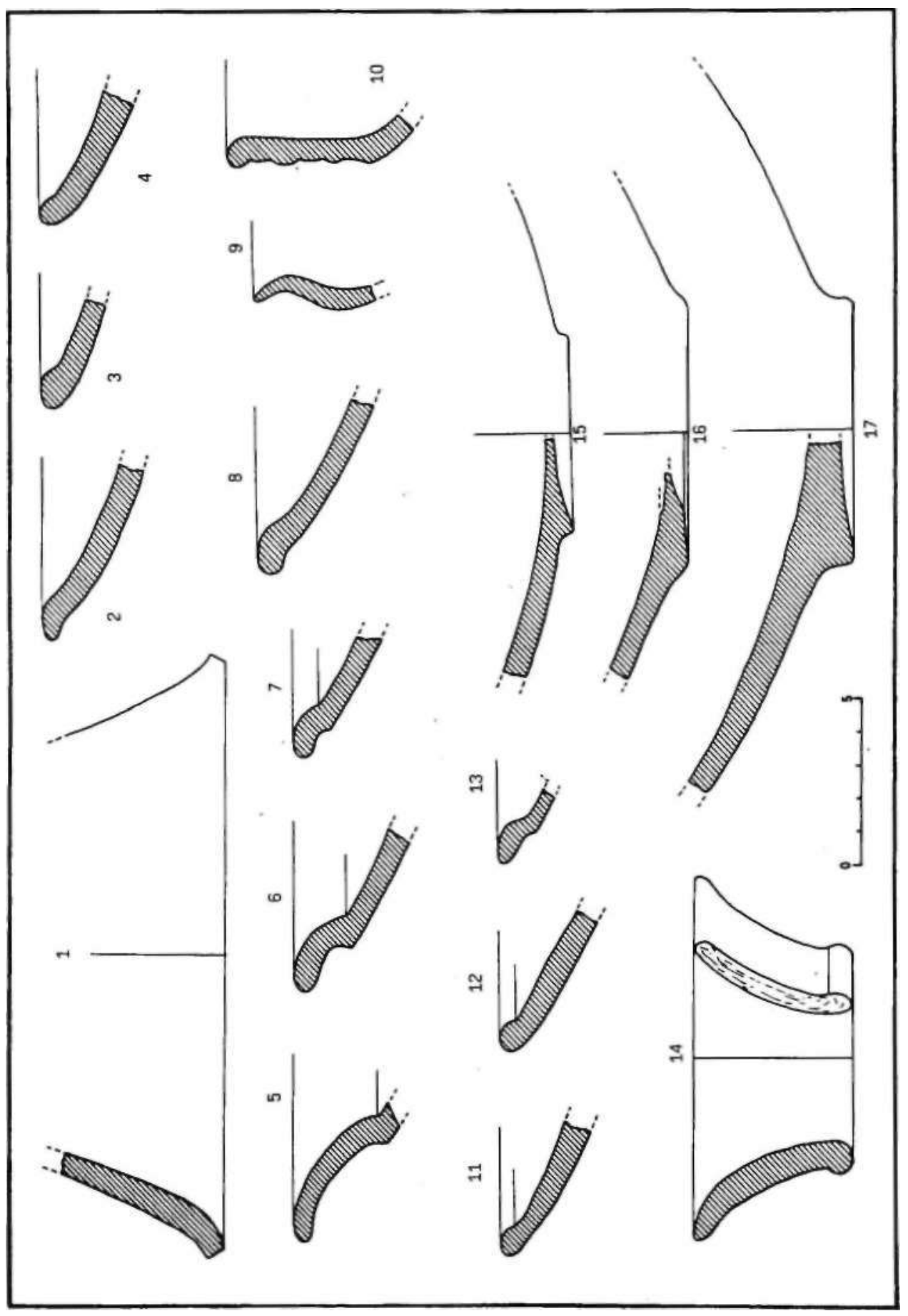

Figura 11

--- Grupo de investigación P.A.I. HUM 236 | http://www.arqueocordoba.com/publ/anales.htm --- 